\title{
Electroencephalographic Finding in Idiopathic REM Sleep Behavior Disorder
}

\author{
Yuichi Inoue $^{a}$ Taeko Sasai $^{a}$ Koichi Hirata ${ }^{b}$

 \\ University, Tochigi, Japan
}

\begin{abstract}
Key Words
Electroencephalography · Idiopathic form - Power spectral analysis - Mild cognitive impairment - REM - Sleep behavior disorder $\cdot a-$ Synucleinopathies
\end{abstract}

\begin{abstract}
The REM sleep behavior disorder (RBD) is a type of parasomnia manifested by vivid, often frightening dreams associated with motor behaviors during REM sleep, sometimes causing injuries to patients themselves or to their bed partners. The polysomnographic features of RBD include increased muscle activity during REM sleep (REM sleep without atonia). The majority of RBD-affected persons are older men. The disorder might be idiopathic (iRBD) or secondary to neurological disorders of various kinds. iRBD management with pharmaceutical measures is usually straightforward and effective. Several longitudinal studies have revealed that a high proportion of iRBD patients convert to a-synucleinopathies such as Parkinson's disease and dementia with Lewy body disease (DLB). Considering this, many studies have been conducted to identify common clinical markers between a-synucleinopathies and iRBD or indicators for the future development of a-synucleinopathies in iRBD patients. In this context, electroencephalographic (EEG) slowing occurring while awake and asleep, which is frequently observed in DLB, has received much attention. Clarification of the association between EEG slowing and the presence of mild cognitive impairment, which is also commonly seen in early
\end{abstract}

stages of DLB, has been particularly expected to offer a breakthrough for the identification of cases which might convert to a-synucleinopathies. In this article, we introduce the progress in quantitative EEG research in iRBD during the past decade. We also discuss the relationship between EEG findings and cognitive decline as well as the mechanisms of EEG changes or cognitive abnormalities in patients with the disorder.

(c) 2015 S. Karger AG, Basel

\section{Disease Concept, Prevalence and Clinical Correlates of the REM Sleep Behavior Disorder}

The REM sleep behavior disorder (RBD) is characterized by dream-enacting behaviors during REM sleep with increased muscle activity in the submentalis or limb muscle (REM sleep without atonia) [1]. Violent behaviors associated with RBD can result in repeated injury, including ecchymoses, lacerations and fractures. The disorder, which affects mainly older men, may occur alone [idiopathic RBD (iRBD)] or in association with various neurological disorders.

A previous study including a phone survey of $>4,900$ people aged 15-100 years indicated an overall prevalence of violent behavior in this population during sleep of $2 \%$ [2]. One quarter of them were regarded as having RBD, giving an overall prevalence of RBD of $0.5 \%$. Another survey estimated the prevalence of RBD as $0.38 \%$ in elderly

\begin{tabular}{|c|c|}
\hline KARGER 125 & $\begin{array}{l}\text { (c) } 2015 \text { S. Karger AG, Basel } \\
0302-282 X / 15 / 0711-0025 \$ 39.50 / 0\end{array}$ \\
\hline $\begin{array}{l}\text { E-Mail karger@karger.com } \\
\text { www.karger.com/nps }\end{array}$ & $\begin{array}{l}\text { This is an Open Access article licensed under the terms of the } \\
\text { Creative Commons Attribution-NonCommercial 3.0 Un- } \\
\text { ported license (CC BY-NC) (www.karger.com/OA-license), } \\
\text { applicable to the online version of the article only. Distribu- } \\
\text { tion permitted for non-commercial purposes only. }\end{array}$ \\
\hline
\end{tabular}

Yuichi Inoue

Tokyo Medical University

6-1-1 Shinjuku

Shinjuku-ku, Tokyo (Japan)

E-Mail inoue@somnology.com 


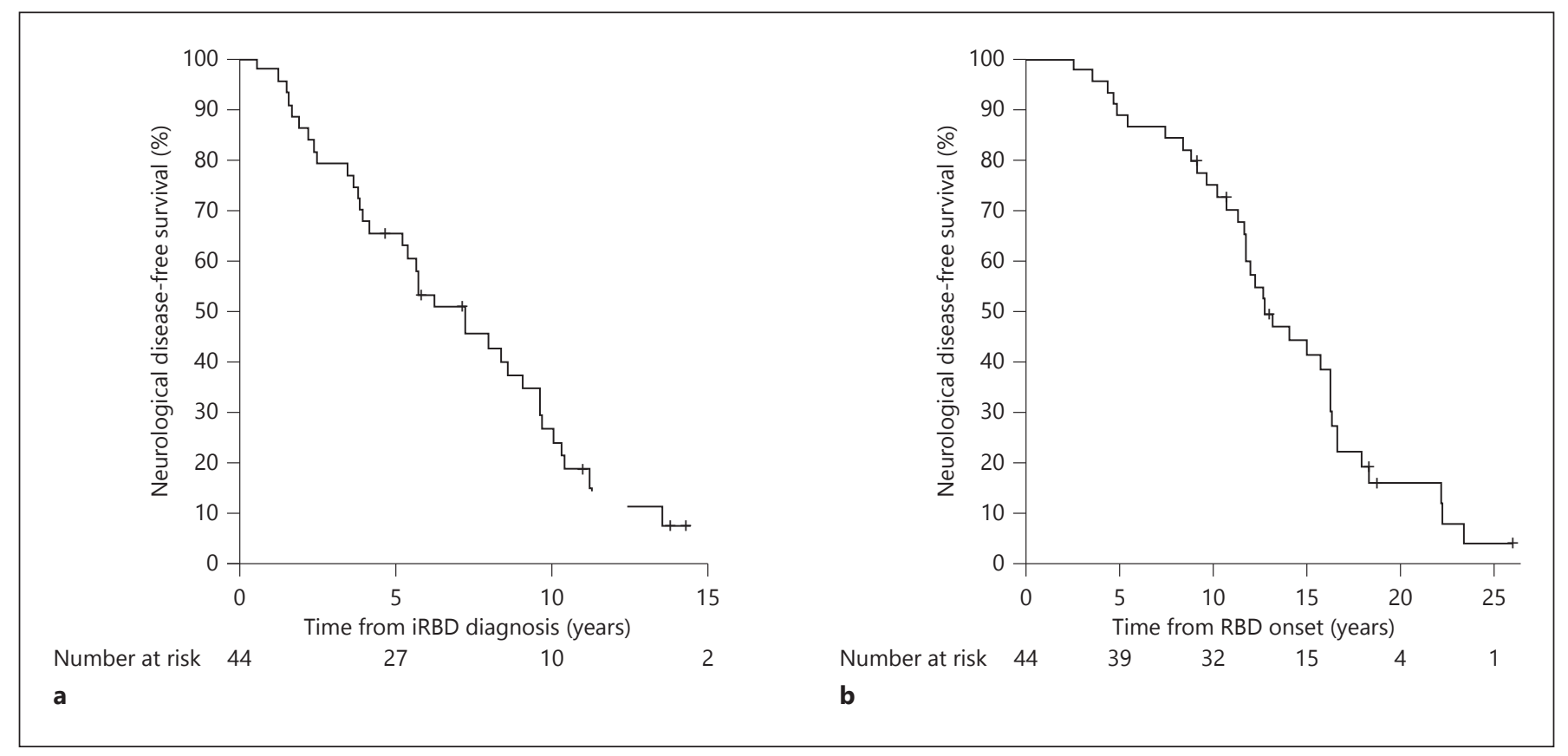

Fig. 1. Rates of neurological-disease-free survival according to the time of iRBD diagnosis (a) and estimated RBD onset (b).

people [3]. These rates imply that the disorder is rare among the general population. However, one recent study from Korea using video-polysomnography (PSG) showed that the prevalence rate of RBD was $2.01 \%$. Moreover, the rate of subclinical RBD, in which increased muscle activities are clearly observed with no history of abnormal REM sleep behavior, was estimated as $4.95 \%$ in elderly Koreans [4], suggesting that a nonnegligible number of people are affected by the disorder.

Of note, RBD has been reported as strongly associated with a category of $\alpha$-synucleinopathies, such as Parkinson's disease (PD), dementia with Lewy body disease (DLB) and multiple system atrophy [5-12]. Results from longitudinal studies from three different groups have shown that a large proportion of patients with iRBD at baseline eventually presented with $\alpha$-synucleinopathies at the long-term follow-up $[7,8,13,14]$. In the first series, $\mathrm{PD}$ developed in 11 (38\%) of 29 patients nearly 4 years after the diagnosis of iRBD [5]. After 16 additional years of follow-up, 21 patients with iRBD from the original cohort developed PD, DLB or multiple system atrophy [13]. In the second series, 26 (28\%) of 93 patients with $\mathrm{iRBD}$ developed PD, DLB or multiple system atrophy after a mean follow-up of 5 years [8]. In the third series of studies done by Iranzo et al. [7], 20 (45\%) of 44 patients with iRBD developed a defined neurodegenera- tive syndrome after a mean follow-up of 5 years. Their recent report with 7 years of additional follow-up has demonstrated that most of the patients diagnosed with iRBD at baseline developed a defined neurodegenerative syndrome (fig. 1) [14]. These very high rates of conversion strongly suggest that iRBD represents a prodromal phase of $\alpha$-synucleinopathies.

Many potential markers are related to early stages of a-synucleinopathies, including sensory, motor, autonomic functional, olfactory and cognitive dysfunction, as well as structural and functional neuroimaging [15-21]. However, these markers are not present in all iRBD patients, suggesting considerable heterogeneity, which reduces the capacity of these markers to identify which iRBD patients are at the highest risk of developing $\alpha$-synucleinopathies.

Considering that quantitative electroencephalographic (EEG) analysis has been regarded as a useful tool for characterizing patients in early-stage Alzheimer's disease, DLB and PD with dementia [22], many researchers have aimed to ascertain possible associations of quantitative EEG findings while both awake and asleep to cognitive findings or descriptive RBD variables [23-25]. Here, we introduce the progress in quantitative EEG research in iRBD during the past decade and discuss the clinical significance and mechanism of abnormal EEG findings in patients with the disorder. 


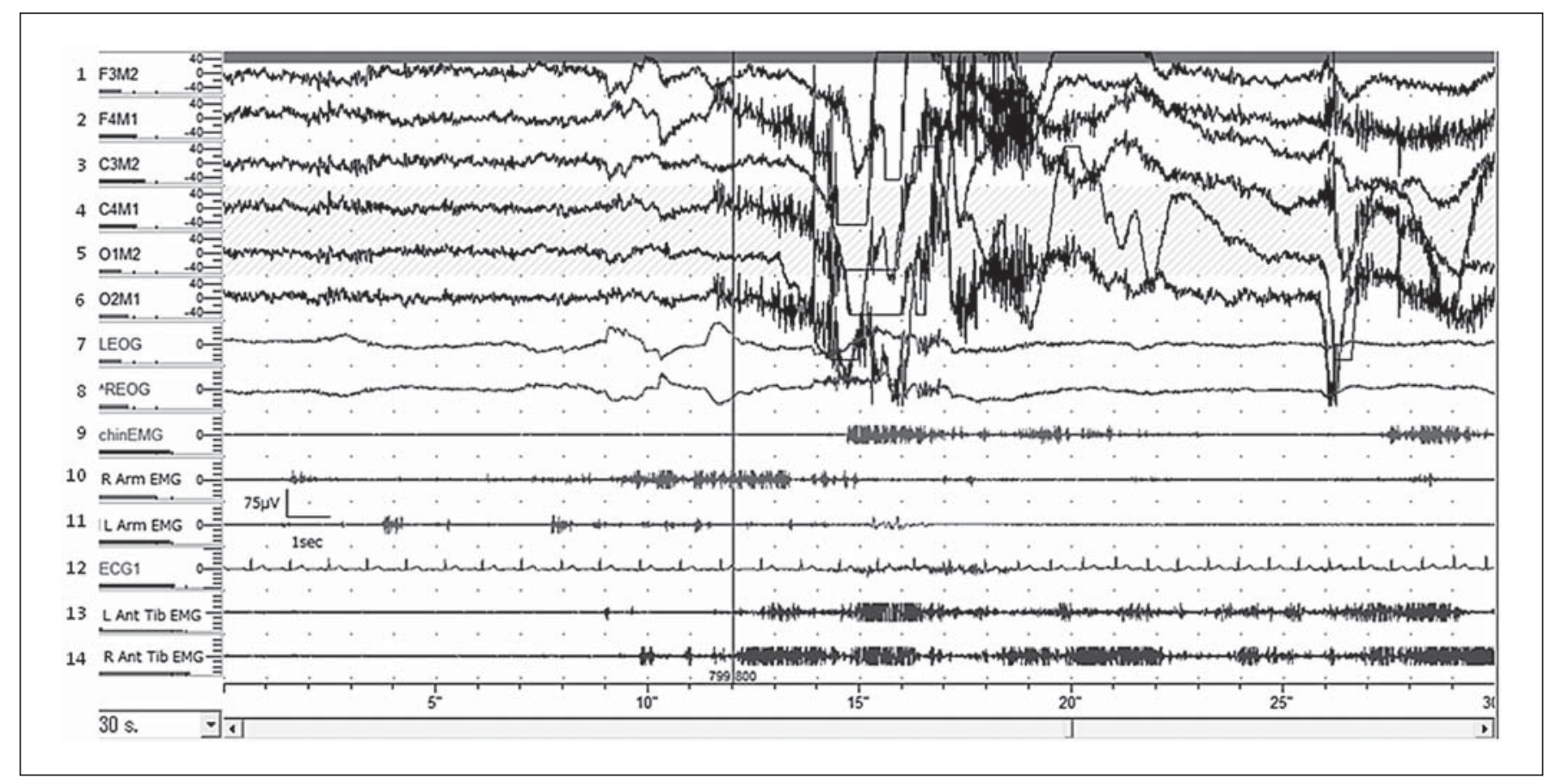

Fig. 2. REM sleep PSG showing submental EMG activity (9) despite the emergence of gross arm and leg movements that are noted by the technician and reflected by prominent twitching in the upper and lower extremity EMGs $(10,11,13,14)$. REM $(7,8)$ im- mediately precedes the onset of complex behavior. $\mathrm{F}=$ Frontal; $\mathrm{M}=$ mastoid $; \mathrm{C}=$ central $\mathrm{O}=$ occipital LEOG/REOG = left $/$ right electrooculogram; Ant Tib $=$ anterior tibialis.

\section{Quantitative and Qualitative EEG Findings in iRBD}

The diagnosis of $\mathrm{RBD}$ requires confirmation not only of the existence of dream enactment behavior with a thorough clinical interview but also PSG-determined positivity for REM sleep without atonia (fig. 2) [26]. Reportedly, a normal non-REM (NREM)-REM cycle is well maintained in patients with iRBD [27], and REM sleep without atonia, in which phasic electromyographic (EMG) activity defined as 3-second mini-epochs including phasic EMG activity with any burst of EMG activity lasting between 0.1 and $5.0 \mathrm{~s}$ and an amplitude exceeding twice the background EMG activity, or tonic EMG activity with an amplitude of at least twice the background EMG muscle tone or more than $10 \mu \mathrm{V}$ for more than $50 \%$ of a 30-second epoch, is mixed into normal REM episodes. In the upcoming third edition of The International Classification of Sleep Disorders (ICSD-3), any (tonic/ phasic) chin EMG activity combined with bilateral phasic activity of the flexor digitorum superficialis muscles in $>27 \%$ of REM sleep, scored in 30 -second epochs, is recommended to distinguish $\mathrm{RBD}$ patients reliably from controls [28].
Slow-wave sleep is thought to play an important role in memory consolidation, brain plasticity, synapse strength and sleep homeostasis [29-31]. In previous studies, PSG findings of patients with iRBD indicated an increased percentage of slow-wave sleep [32, 33]. In 2005, MassicotteMarquez et al. [24] reported that iRBD patients spent more time in slow-wave sleep on PSG compared with controls. Their spectral analysis also demonstrated that iRBD patients had increased all-night $\delta$ power in comparison with controls. Based on these findings, they speculated that abnormal EEG patterns during slow-wave sleep, possibly due to cortical neural desynchronization, might constitute a physiological marker of iRBD. However, the same team reported a negative result to this finding in 2011 [34]. As the reason for this discrepancy, they stated that they had possibly overlooked early parkinsonism or dementia in the subjects examined in the prior study. Consequently, abnormality of EEG during NREM is minimal or absent, suggesting that the neurophysiological substrates responsible for NREM sleep are preserved in iRBD.

Different from slow-wave sleep, substantial EEG abnormality during REM sleep and wakefulness of patients with iRBD has been reported by several researchers. In 
2003, Fantini et al. [23] reported that, during wakefulness, iRBD patients showed a considerably higher $\theta$ power in frontal, temporal and occipital regions with a lower $\beta$ power in the occipital region compared with age-matched elderly controls. The dominant occipital frequency was significantly lower in iRBD. Results also indicate that $\beta$ power in the occipital region during REM sleep was lower in the affected patients. That study was the first to show impaired cortical activation during both wakefulness and REM sleep in $\mathrm{iRBD}$ although changes in sleep architecture were absent. The results were replicated by studies conducted in later years $[25,35]$.

When interpreting EEG findings of iRBD patients, the age effect on EEG slowing must be considered $[36,37]$ because most iRBD-affected people are elderly. To clarify this issue, we conducted a similar EEG power spectral analysis in younger iRBD patients ( $60.5 \pm 5.3$ years) and age-matched controls [35]. The results demonstrated that iRBD patients exhibited significantly lower $\alpha$ and $\beta$ power in the central and occipital regions during wakefulness and REM stage (but not during NREM sleep) than controls (fig. 3) [35]. Although clearly increased power in the lowfrequency band was not seen in our patients, this finding raised the possibility of the existence of decreased cortical activation, even in this young $\mathrm{iRBD}$ patient population.

\section{Relationship between EEG Slowing and Cognitive Impairment in iRBD}

Mild cognitive impairment (MCI), which is characterized by cognitive deficits that do not interfere with daily activities, is a transitional stage between normal aging and dementia. This condition is generally accepted as an important risk factor for developing dementia [38]. MCI with deficits in visuospatial function, attention/executive function, verbal episodic memory or nonverbal memory occurs in approximately $50 \%$ of iRBD patients, a rate that is markedly higher than the $8 \%$ found in age- and sexmatched healthy controls $[39,41]$. The type of MCI most frequently encountered in iRBD is single-domain nonamnestic MCI. However, results vary across studies depending on which cognitive domain is impaired (table 1) [39]. Population heterogeneity, small sample sizes and the use of different cognitive tasks with variable sensitivity to detect deficits and variable specificity to a cognitive domain might explain these discrepancies. However, in general, attention, executive functions, episodic verbal memory (mainly free-recall capacities) and nonverbal learning are the most affected domains in iRBD [43]. In addition, two recent studies have revealed that iRBD patients have impaired decision making ability, a frontal-related cognitive function, irrespective of other cognitive variables [44, 45].

EEG slowing in an awake state and REM sleep might represent an early stage of central nervous system dysfunction, perhaps associated with cognitive decline. The Montreal team investigated the relation between the result of waking EEG spectral analysis and the cognitive variables in 42 untreated iRBD patients [46]. That study found that RBD + MCI patients had a higher slow-to-fast EEG frequency ratio than RBD - MCI patients and controls in the parietal, temporal and occipital regions. $\mathrm{RBD}+\mathrm{MCI}$ patients also had higher relative $\theta$ power in the parietal, temporal and occipital regions, and lower relative a power in the occipital region compared to RBD - MCI patients and controls. Moreover, RBD + MCI patients had higher relative $\theta$ power in the frontal and central area and lower relative $\beta$ power in the central, parietal and temporal regions compared to controls. The dominant occipital frequency was also slower in RBD + MCI patients compared to controls. It is particularly interesting that no between-group differences were observed between RBD - MCI and controls. These findings strongly affected the relationship between cognitive decline and EEG slowing in patients with iRBD. In line with this report, our study also revealed that MCI determined using the Montreal cognitive assessment scale [47] was observed in more than $75 \%$ of the iRBD patients, and that age and $\log (\theta$ power during REM sleep) was significantly associated with the this score in multiple regression analysis in this patients population [35]. In addition, a decrease in the score of the Sniffin' Stick test (thresholddiscrimination-identification score), which is known as an early LBD marker [48], was significantly associated with the Montreal cognitive assessment score in this analysis. The results presented in these two reports support the idea that EEG slowing during wakefulness or REM sleep is related with the process of cognitive decline possibly brought about by Lewy body pathology.

However, EEG slowing in iRBD can be hypothesized as an indicator for the future development of cognitive dysfunction. To test this hypothesis, Iranzo et al. [25] blindly quantified EEG spectral power from PSG findings of $23 \mathrm{iRBD}$ patients without MCI and 10 healthy controls. After a mean follow-up of 2.4 years from the baseline evaluation, 10 patients developed MCI (RBD + MCI) and 13 patients continued to show normal cognitive function (idiopathic at follow-up). Patients with RBD $+\mathrm{MCI}$ had marked EEG slowing (increased $\theta$ and $\delta$ activity) in central and occipital regions during wakefulness and REM
Inoue/Sasai/Hirata 

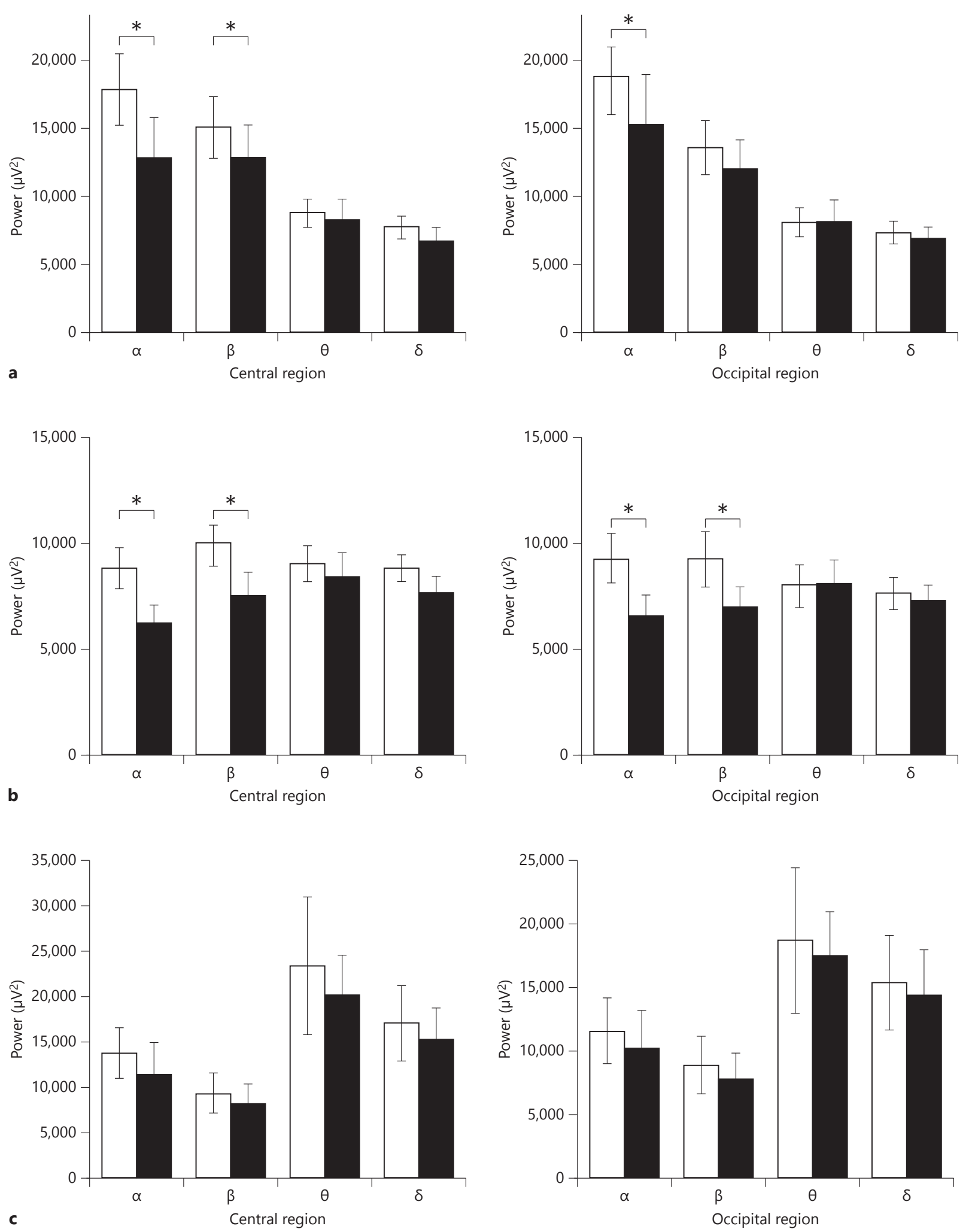

Fig. 3. Comparison of EEG spectral power during wake (a), REM sleep (b) and NREM sleep (c) in patients with iRBD and controls. $\mathbf{\square}=$ Younger RBD group; $\square=$ age-matched control group. ${ }^{*} \mathrm{p}<0.05$, means \pm SD. 
Table 1. Controlled studies of cognitive performance in iRBD

\begin{tabular}{|c|c|c|c|c|c|c|}
\hline Attention/executive functions & Yes & Yes & Yes & Yes & Yes & Yes \\
\hline Verbal episodic memory & Yes & Yes & Yes & Yes & Yes & Yes \\
\hline Nonverbal memory & Yes & - & - & - & Yes & Yes \\
\hline
\end{tabular}

Yes $=$ Patients show poorer performance than controls $(\mathrm{p}<0.05)$; No $=$ similar performance between patients and controls.

a, b Share common participants.

sleep at baseline, particularly in the right hemisphere, in comparison with controls and, to a lesser degree, iRBD patients without MCI at the follow-up. The EEG spectral pattern of the RBD + MCI group was similar to that found in patients with DLB or PD associated with dementia [22, 49]. Based on these findings, they speculated that the presence of EEG slowing on spectral analysis might predict the development of MCI within a short period in patients initially receiving a diagnosis of iRBD.

\section{Mechanism of EEG Slowing and Cognitive Decline in iRBD}

To describe the mechanism of EEG slowing and cognitive decline in $\mathrm{RBD}$ patients, one must consider some functional or anatomical abnormalities in the brain. The pathogenesis of iRBD and the neurobiological significance of the cognitive decline and EEG slowing have not been clearly elucidated. Evidence of the involvement of several brain stem structures mainly located in the pons, which include the ventral mesopontine junction, the pedunculopontine nucleus, the laterodorsal tegmental nucleus, the locus ceruleus (LC) and the peri-LC area, derives from animal models $[50,51]$ and from neuropathological observations in human RBD [52-54]. The pedunculopontine nucleus and the LC, which represent the largest clusters of cholinergic and noradrenergic neurons within the brain stem reticular formation, respectively, are known to play a role in arousal, cortical activation and cognitive function, including attentional processes [55-58]. Therefore, a dysfunctioning cholinergic subcortical system might contribute to cognitive impairment and EEG slowing in iRBD patients. The fact that cholinergic activity promotes REM sleep, in which EEG slowing was observed in the studies described above [23, $25,35]$, and that cholinergic denervation of the limbic cortex is a robust determinant of hyposmia [59], which was recognized in our study using threshold-discrimination-identification scores on Sniffin' Stick tests [35], might support this idea.

In vivo evaluation of some cholinergic circuits of the human brain has recently been introduced using a transcranial magnetic stimulation protocol that might yield information about the function of some cholinergic circuits in the human brain. This technique relies on short latency afferent inhibition (SAI) off the motor cortex [60]. SAI is significantly reduced in hypocholinergic forms of dementia, such as dementia of the Alzheimer type, DLB and MCI. In these patients, it can be increased by administration of acetylcholinesterase inhibitors [61-63]. Based on the hypothesis that cognitive performance and cortical activation in iRBD patients are associated with a dysfunctioning cholinergic system, Nardone et al. [64] applied the SAI technique in a group of 10 mostly drug-naïve iRBD patients (MCI was observed in 6 of them) and a group of 15 age-matched healthy controls. They found that mean SAI was significantly reduced in patients with iRBD compared with the controls, and that those SAI values correlated strongly with tests measuring episodic verbal memory and executive functions. This finding also supports the hypothesis of cholinergic dysfunction in some patients with $\mathrm{iRBD}$ who develop cognitive impairment.

Abnormalities in central cholinergic functions, as well as EEG slowing and cognitive decline in iRBD patients, might be caused either by cortical pathology or damage to the brain stem structure that regulates REM sleep and activates the neocortex $[23,24]$. Several neuropathological studies performed on iRBD patients have shown neural alterations in several brain stem nuclei (i.e. substantia nig- 
ra, pedunculopontine nucleus and the LC-sub-LC complex). All of these brain stem structures have diffuse projections to the cerebral cortex, and perturbations in these neural networks might explain the presence of cognitive decline or EEG slowing. A recent single-photon emission computed tomography study [65] revealed that iRBD + MCI patients showed hypoperfusion in the occipital cunei and superior temporal gyri compared to iRBD - MCI patients and controls, suggesting an underlying anatomical substrate specific to the presence of $\mathrm{MCI}$ in $\mathrm{iRBD}$, which can also explain the mechanism of the EEG slowing. A diffusion tensor imaging study revealed microstructural changes in the white matter, particularly in the left superior temporal lobe and the right occipital lobe [66]. In addition, studies using voxel-based morphometry showed gray matter density anomalies in both hippocampi and the left parahippocampal gyrus in iRBD patients $[67,68]$. This evidence suggests that structural changes in the brain are responsible for EEG slowing and cognitive decline, although none of these studies simultaneously conducted cognitive function measurements and quantitative EEG analyses during both wakefulness and sleep.

\section{Concluding Remarks}

To date, few studies have examined longitudinal changes in the cognitive function of iRBD patients [14, $69,70]$, and no conclusive information has been obtained. Moreover, no study has evaluated changes in quantitative EEG findings along with the disease course of RBD. Thus, it remains unclear whether EEG slowing and deteriorated cognitive variables in iRBD represent a true early marker of subsequent development of $\alpha$-synucleinopathies. The scientific community interested in RBD requires further efforts to clarify this issue.

\section{Disclosure Statement}

This work was supported by JSPS KAKENHI grant No. 25515009.

Dr. Inoue also reports an Intramural Research Grant (21B-4) for Neurological and Psychiatric Disorders from the National Center of Neurology and Psychiatry, but there is no conflict of interest for this study. Dr. Hirata and Dr. Sasai report no conflicts requiring disclosure.

\section{References}

1 Gagnon JF, Postuma RB, Mazza S, Doyon J, Montplaisir J: Rapid-eye-movement sleep behaviour disorder and neurodegenerative diseases. Lancet Neurol 2006;5:424-432.

-2 Ohayon MM, Caulet M, Priest RG: Violent behavior during sleep. J Clin Psychiatry 1997; 58:369-376; quiz 377.

-3 Chiu HF, Wing YK: REM sleep behaviour disorder: an overview. Int J Clin Pract 1997;51: 451-454.

4 Kang SH, Yoon IY, Lee SD, Han JW, Kim TH, Kim KW: REM sleep behavior disorder in the Korean elderly population: prevalence and clinical characteristics. Sleep 2013;36:11471152.

5 Schenck CH, Bundlie SR, Mahowald MW: Delayed emergence of a parkinsonian disorder in $38 \%$ of 29 older men initially diagnosed with idiopathic rapid eye movement sleep behaviour disorder. Neurology 1996;46:388393.

-6 Boeve BF, Silber MH, Ferman TJ, Lucas JA, Parisi JE: Association of REM sleep behavior disorder and neurodegenerative disease may reflect an underlying synucleinopathy. Mov Disord 2001;16:622-630.

7 Iranzo A, Molinuevo JL, Santamaria J, Serradell M, Marti MJ, Valldeoriola F, Tolosa E: Rapid-eye-movement sleep behaviour disorder as an early marker for a neurodegenerative disorder: a descriptive study. Lancet Neurol 2006;5:572-577.
8 Postuma RB, Gagnon JF, Vendette M, Fantini ML, Massicotte-Marquez J, Montplaisir J: Quantifying the risk of neurodegenerative disease in idiopathic REM sleep behavior disorder. Neurology 2009;72:1296-1300.

-9 Comella CL, Nardine TM, Diederich NJ, Stebbins GT: Sleep-related violence, injury, and REM sleep behavior disorder in Parkinson's disease. Neurology 1998;51:526529.

10 Gagnon JF, Bedard MA, Fantini ML, Petit D, Panisset M, Rompre S, Carrier J, Montplaisir $\mathrm{J}$ : REM sleep behavior disorder and REM sleep without atonia in Parkinson's disease. Neurology 2002;59:585-589.

11 Gagnon JF, Montplaisir J, Bedard MA:Rapideye-movement sleep disorders in Parkinson's disease (in French). Rev Neurol (Paris) 2002; 158:135-152.

-12 Boeve BF, Silber MH, Ferman TJ, Kokmen E, Smith GE, Ivnik RJ, Parisi JE, Olson EJ, Petersen RC: REM sleep behavior disorder and degenerative dementia: an association likely reflecting Lewy body disease. Neurology 1998;51:363-370.

13 Schenck CH, Boeve BF, Mahowald MW: Delayed emergence of a parkinsonian disorder or dementia in $81 \%$ of older men initially diagnosed with idiopathic rapid eye movement sleep behavior disorder: a 16-year update on a previously reported series. Sleep Med 2013; 14:744-748.
14 Iranzo A, Tolosa E, Gelpi E, Molinuevo JL Valldeoriola F, Serradell M, Sanchez-Valle R, Vilaseca I, Lomena F, Vilas D, Llado A, Gaig C, Santamaria J: Neurodegenerative disease status and post-mortem pathology in idiopathic rapid-eye-movement sleep behaviour disorder: an observational cohort study. Lancet Neurol 2013;12:443-453.

-15 Ferini-Strambi L, Di Gioia MR, Castronovo V, Oldani A, Zucconi M, Cappa SF: Neuropsychological assessment in idiopathic REM sleep behavior disorder (RBD): does the idiopathic form of RBD really exist? Neurology 2004;62:41-45.

16 Massicotte-Marquez J, Decary A, Gagnon JF, Vendette M, Mathieu A, Postuma RB, Carrier J, Montplaisir J: Executive dysfunction and memory impairment in idiopathic REM sleep behavior disorder. Neurology 2008;70:1250-1257.

-17 Stiasny-Kolster K, Doerr Y, Moller JC, Hoffken H, Behr TM, Oertel WH, Mayer G: Combination of 'idiopathic' REM sleep behaviour disorder and olfactory dysfunction as possible indicator for alpha-synucleinopathy demonstrated by dopamine transporter FPCIT-SPECT. Brain 2005;128:126-137.

18 Eisensehr I, Linke R, Noachtar S, Schwarz J, Gildehaus FJ, Tatsch K: Reduced striatal dopamine transporters in idiopathic rapid eye movement sleep behaviour disorder. Comparison with Parkinson's disease and controls. Brain 2000;123:1155-1160. 
19 Eisensehr I, Linke R, Tatsch K, Kharraz B, Gil- 32 Olson EJ, Boeve BF, Silber MH: Rapid eye dehaus JF, Wetter CT, Trenkwalder C, Schwarz J, Noachtar S: Increased muscle activity during rapid eye movement sleep correlates with decrease of striatal presynaptic dopamine transporters. IPT and IBZM SPECT imaging in subclinical and clinically manifest idiopathic REM sleep behavior disorder, Parkinson's disease, and controls. Sleep 2003;26:507-512.

20 Miyamoto T, Miyamoto M, Inoue Y, Usui Y, Suzuki K, Hirata K: Reduced cardiac ${ }^{123} \mathrm{I}-$ MIBG scintigraphy in idiopathic REM sleep behavior disorder. Neurology 2006;67:22362238.

21 Miyamoto T, Miyamoto M, Suzuki K, Nishibayashi M, Iwanami M, Hirata K: ${ }^{123} \mathrm{I}-$ MIBG cardiac scintigraphy provides clues to the underlying neurodegenerative disorder in idiopathic REM sleep behavior disorder. Sleep 2008;31:717-723.

22 Bonanni L, Thomas A, Tiraboschi P, Perfetti $B$, Varanese S, Onofrj M: EEG comparisons in early Alzheimer's disease, dementia with Lewy bodies and Parkinson's disease with dementia patients with a 2 -year follow-up. Brain 2008;131:690-705.

23 Fantini ML, Gagnon JF, Petit D, Rompre S, Decary A, Carrier J, Montplaisir J: Slowing of electroencephalogram in rapid eye movement sleep behavior disorder. Ann Neurol 2003;53:774-780.

24 Massicotte-Marquez J, Carrier J, Decary A, Mathieu A, Vendette M, Petit D, Montplaisir J: Slow-wave sleep and delta power in rapid eye movement sleep behavior disorder. Ann Neurol 2005;57:277-282.

-25 Iranzo A, Isetta V, Molinuevo JL, Serradell M, Navajas D, Farre R, Santamaria J: Electroencephalographic slowing heralds mild cognitive impairment in idiopathic REM sleep behavior disorder. Sleep Med 2010;11:534539.

-26 Kryger M, Roth T, Dement W: Principles and Practice of Sleep Medicine, ed 5. Philadelphia, Saunders, 2010

-27 Tachibana N, Sugita Y, Terashima K, Teshima Y, Shimizu T, Hishikawa Y: Polysomnographic characteristics of healthy elderly subjects with somnambulism-like behaviors. Biol Psychiatry 1991;30:4-14.

28 Boeve BF: REM sleep behavior disorder: updated review of the core features, the REM sleep behavior disorder-neurodegenerative disease association, evolving concepts, controversies, and future directions. Ann NY Acad Sci 2010;1184:15-54.

29 Steriade M: Grouping of brain rhythms in corticothalamic systems. Neuroscience 2006; 137:1087-1106.

30 Tononi G, Cirelli C: Sleep function and synaptic homeostasis. Sleep Med Rev 2006;10: 49-62.

-31 Vyazovskiy VV, Olcese U, Lazimy YM, Faraguna U, Esser SK, Williams JC, Cirelli C, Tononi G: Cortical firing and sleep homeostasis. Neuron 2009;63:865-878. movement sleep behaviour disorder: demographic, clinical and laboratory findings in 93 cases. Brain 2000;123:331-339. bach D, Behroozi B: Rapid eye movement (REM) sleep behavior disorder: a sleep disturbance affecting mainly older men. Isr J Psychiatry Relat Sci 2002;39:28-35.

34 Latreille V, Carrier J, Montplaisir J, Lafortune M, Gagnon JF: Non-rapid eye movement sleep characteristics in idiopathic REM sleep behavior disorder. J Neurol Sci 2011;310:159162.

35 Sasai T, Matsuura M, Inoue Y: Electroencephalographic findings related with mild cognitive impairment in idiopathic rapid eye movement sleep behavior disorder. Sleep 2013;36: 1893-1899.

36 Tucker DM, Penland JG, Sandstead HH, Milne DB, Heck DG, Klevay LM: Nutrition status and brain function in aging. Am J Clin Nutr 1990;52:93-102.

37 Ehlers CL, Kupfer DJ, Buysse DJ, Cluss PA, Miewald JM, Bisson EF, Grochocinski VJ: The Pittsburgh study of normal sleep in young adults: focus on the relationship between waking and sleeping EEG spectral patterns. Electroencephalogr Clin Neurophysiol 1998;106:199-205.

38 Gauthier S, Reisberg B, Zaudig M, Petersen RC, Ritchie K, Broich K, Belleville S, Brodaty $\mathrm{H}$, Bennett D, Chertkow H, Cummings JL, de Leon M, Feldman H, Ganguli M, Hampel H, Scheltens P, Tierney MC, Whitehouse P, Winblad B; International Psychogeriatric Association Expert Conference on Mild Cognitive Impairment: mild cognitive impairment. Lancet 2006;367:1262-1270.

39 Gagnon JF, Bertrand JA, Genier Marchand D: Cognition in rapid eye movement sleep behavior disorder. Front Neurol 2012;3:82.

40 Terzaghi M, Sinforiani E, Zucchella C, Zambrelli E, Pasotti C, Rustioni V, Manni R: Cognitive performance in REM sleep behaviour disorder: a possible early marker of neurodegenerative disease? Sleep Med 2008;9:343351.

41 Gagnon JF, Vendette M, Postuma RB, Desjardins C, Massicotte-Marquez J, Panisset M, Montplaisir J: Mild cognitive impairment in rapid eye movement sleep behavior disorder and Parkinson's disease. Ann Neurol 2009;66: $39-47$.

42 Marques A, Dujardin K, Boucart M, Pins D, Delliaux M, Defebvre L, Derambure P, Monaca C: REM sleep behaviour disorder and visuoperceptive dysfunction: a disorder of the ventral visual stream? J Neurol 2010;257:383391.

43 Frauscher B, Iranzo A, Gaig C, Gschliesser V, Guaita M, Raffelseder V, Ehrmann L, Sola N, Salamero M, Tolosa E, Poewe W, Santamaria J, Hogl B; SINBAR (Sleep Innsbruck Barcelona) Group: Normative EMG values during REM sleep for the diagnosis of REM sleep behavior disorder. Sleep 2012;35:835-847.
33 Oksenberg A, Radwan H, Arons E, Hoffen-
44 Sasai T, Miyamoto T, Miyamoto M, Iwanami M, Abe T, Matsuura M, Inoue Y: Impaired decision-making in idiopathic REM sleep behavior disorder. Sleep Med 2012;13:301-306.

45 Delazer M, Hogl B, Zamarian L, Wenter J, Ehrmann L, Gschliesser V, Brandauer E, Poewe W, Frauscher B: Decision making and executive functions in REM sleep behavior disorder. Sleep 2012;35:667-673.

46 Rodrigues Brazete J, Montplaisir J, Petit D, Postuma RB, Bertrand JA, Genier Marchand D, Gagnon JF: Electroencephalogram slowing in rapid eye movement sleep behavior disorder is associated with mild cognitive impairment. Sleep Med 2013;14:1059-1063.

47 Gill DJ, Freshman A, Blender JA, Ravina B: The Montreal cognitive assessment as a screening tool for cognitive impairment in Parkinson's disease. Mov Disord 2008;23: 1043-1046.

48 Haehner A, Hummel T, Hummel C, Sommer U, Junghanns S, Reichmann H: Olfactory loss may be a first sign of idiopathic Parkinson's disease. Mov Disord 2007;22:839-842.

49 Barber PA, Varma AR, Lloyd JJ, Haworth B, Snowden JS, Neary D: The electroencephalogram in dementia with Lewy bodies. Acta Neurol Scand 2000;101:53-56.

50 Jouvet M, Delorme F: Locus coeruleus et sommeil paradoxal. CR Soc Biol 1965;159:895899.

51 Hendricks JC, Morrison AR, Mann GL: Different behaviors during paradoxical sleep without atonia depend on pontine lesion site. Brain Res 1982;239:81-105.

52 Uchiyama M, Isse K, Tanaka K, Yokota N, Hamamoto M, Aida S, Ito Y, Yoshimura M, Okawa M: Incidental Lewy body disease in a patient with REM sleep behavior disorder. Neurology 1995;45:709-712.

53 Turner RS, D'Amato CJ, Chervin RD, Blaivas M: The pathology of REM sleep behavior disorder with comorbid Lewy body dementia. Neurology 2000;55:1730-1732.

54 Arnulf I, Bonnet AM, Damier P, Bejjani BP, Seilhean D, Derenne JP, Agid Y: Hallucinations, REM sleep, and Parkinson's disease: a medical hypothesis. Neurology 2000;55:281288.

55 Kleiner S, Bringmann A: Nucleus basalis magnocellularis and pedunculopontine tegmental nucleus: control of the slow EEG waves in rats. Arch Ital Biol 1996;134:153167.

56 Steckler T, Inglis W, Winn P, Sahgal A: The pedunculopontine tegmental nucleus: a role in cognitive processes? Brain Res Rev 1994;19: 298-318.

57 Winn P: Frontal syndrome as a consequence of lesions in the pedunculopontine tegmental nucleus: a short theoretical review. Brain Res Bull 1998;47:551-563.

58 Berridge CW, Page ME, Valentino RJ, Foote SL: Effects of locus coeruleus inactivation on electroencephalographic activity in neocortex and hippocampus. Neuroscience 1993;55: 381-393. 
59 Bohnen NI, Muller ML, Kotagal V, Koeppe RA, Kilbourn MA, Albin RL, Frey KA: Olfactory dysfunction, central cholinergic integrity and cognitive impairment in Parkinson's disease. Brain 2010;133:1747-1754.

60 Tokimura H, Di Lazzaro V, Tokimura Y, Oliviero A, Profice P, Insola A, Mazzone P, Tonali P, Rothwell JC: Short latency inhibition of human hand motor cortex by somatosensory input from the hand. J Physiol 2000;523: 503-513.

61 Di Lazzaro V, Oliviero A, Pilato F, Saturno E, Dileone M, Marra C, Ghirlanda S, Ranieri F, Gainotti G, Tonali P: Neurophysiological predictors of long term response to AChE inhibitors in AD patients. J Neurol Neurosurg Psychiatry 2005;76:1064-1069.

-62 Di Lazzaro V, Pilato F, Dileone M, Saturno E, Profice P, Marra C, Daniele A, Ranieri F, Quaranta D, Gainotti G, Tonali PA: Functional evaluation of cerebral cortex in dementia with Lewy bodies. NeuroImage 2007;37:422-429.

63 Nardone R, Bergmann J, Christova M, Caleri F, Tezzon F, Ladurner G, Trinka E, Golaszewski S: Short latency afferent inhibition differs among the subtypes of mild cognitive impairment. J Neural Transm 2012;119:463-471.
64 Nardone R, Bergmann J, Kunz A, Christova M, Brigo F, Tezzon F, Trinka E, Golaszewski $S$ : Cortical afferent inhibition is reduced in patients with idiopathic REM sleep behavior disorder and cognitive impairment: a TMS study. Sleep Med 2012;13:919-925.

65 Vendette M, Montplaisir J, Gosselin N, Soucy JP, Postuma RB, Dang-Vu TT, Gagnon JF: Brain perfusion anomalies in rapid eye movement sleep behavior disorder with mild $\operatorname{cog}$ nitive impairment. Mov Disord 2012;27: 1255-1261.

66 Unger MM, Belke M, Menzler K, Heverhagen JT, Keil B, Stiasny-Kolster K, Rosenow F, Diederich NJ, Mayer G, Moller JC, Oertel WH, Knake S: Diffusion tensor imaging in idiopathic REM sleep behavior disorder reveals microstructural changes in the brainstem, substantia nigra, olfactory region, and other brain regions. Sleep 2010;33:767-773.
67 Scherfler C, Frauscher B, Schocke M, Iranzo A, Gschliesser V, Seppi K, Santamaria J, Tolosa E, Hogl B, Poewe W, Group S: White and gray matter abnormalities in idiopathic rapid eye movement sleep behavior disorder: a diffusion-tensor imaging and voxel-based morphometry study. Ann Neurol 2011;69:400407.

68 Hanyu H, Inoue Y, Sakurai H, Kanetaka H, Nakamura M, Miyamoto T, Sasai T, Iwamoto $\mathrm{T}$ : Voxel-based magnetic resonance imaging study of structural brain changes in patients with idiopathic REM sleep behavior disorder. Parkinsonism Relat Disord 2012; 18:136-139.

69 Manni R, Sinforiani E, Pacchetti C, Zucchella C, Cremascoli R, Terzaghi M: Cognitive dysfunction and REM sleep behavior disorder: key findings in the literature and preliminary longitudinal findings. Int $\mathrm{J}$ Psychophysiol 2013;89:213-217.

70 Fantini ML, Farini E, Ortelli P, Zucconi M, Manconi M, Cappa S, Ferini-Strambi L: Longitudinal study of cognitive function in idiopathic REM sleep behavior disorder. Sleep 2011;34:619-625. 